\author{
Álvaro Cuadra \\ Dr. de la Sorbonne en Letras y Semiología \\ Facultad de Comunicación Social, \\ Universidad Central de Ecuador \\ wynnkott@gmail.com
}

\title{
Universidad y pensamiento crítico: intelectuales e influencers
}

\section{University and critical thinking: intellectuals and influencers}

\section{Resumen}

En este artículo queremos analizar la condición del intelectual y el pensamiento crítico en la hora actual. Para ello se propone examinar la condición de los poetas finiseculares, como Darío y Martí, ante el advenimiento del periodismo moderno. La orientación performativa de las instituciones de educación superior, tanto como la irrupción y expansión de las RSO (Redes Sociales On line) y los influencers, están señalando el ocaso de aquella figura centenaria: el intelectual.

Palabras clave: Intelectual, Influencer, Universidad, Redes Sociales On line

\begin{abstract}
In this article we analyze the condition of intellectual and the critical thinking in our present. For this we propose to examine the condition of the poets from the end of XIX century, like Darío and Martí, in view of advent of modern journalism. The performative orientation of the higher education, as much as the interruption and the expansion of OSN (On-line Social Networks) and influencers, are signaled the sunset of this centenary figure: the intellectual.
\end{abstract}

Keywords: Intellectual, Influencer, University, Virtual On-line Social Networks 
Álvaro Cuadra

\section{La sociedad de los poetas}

A fines del siglo XIX la cultura, en el ámbito latinoamericano, sufrió una gran conmoción que tuvo consecuencias estéticas y políticas. Ángel Rama ha dado buena cuenta de ello a propósito de Rubén Darío (Rama, 1995). En efecto, la irrupción del mercado transformó el régimen de significación prevaleciente hasta 1900. Como escribe Rama:

"La repetida condena del burgués materialista en que unánimemente coinciden los escritores del modernismo, desde los esteticistas que acaudilla Darío - como se puede ver en su cuento "El rey burgués"-, hasta sus objetores, poseídos de la preocupación moral o social, tanto en la línea apostólica de Martí como en la didáctica de Rodó, responde a la más flagrante evidencia de la nueva economía de la época finisecular: la instauración del mercado" (Rama, 1995: 35).

Es interesante destacar que la crisis finisecular que conmueve al modernismo se traduce en el ocaso de los poetas como figuras protagónicas del quehacer cultural de la época:

"Producida la división del trabajo y la instauración del mercado, el poeta hispanoamericano se vio condenado a desaparecer. La alarma fue general. Se acumularon centenares de testimonios denunciando esta situación y señalando el peligro que para la vida espiritual profunda de las sociedades hispanoamericanas comportaba la que se veía como inminente desaparición del arte y la literatura. A los ojos de los poetas, el mundo circundante había sido dominado por un materialismo hostil al espíritu, en lo que no se equivocaban mucho, y si algunos confundieron la fatal quiebra de los valores retóricos del pasado con la extinción misma de la cultura, los más comprendieron agudamente lo que estaba ocurriendo" (Rama, 1995: 37). 
Hagamos notar que, paralelo a este ocaso del poeta, emergía en Francia una figura inédita: el intelectual. Recordemos que en 1898, Èmile Zola escribe su famosa carta $J$ 'Accuse en el diario L'Aurore, dirigida nada menos que al Presidente de la República, lo que le valió un proceso por difamación y un breve exilio en Londres. Mientras tanto, la figura histórica del poeta era degradada a la condición de excrecencia que ya no encuentra sitio en una sociedad burguesa mercantilizada, escribe Rama (1995):

"En las últimas décadas del XIX y comienzos del XX, en ese período propiamente modernista que se cierra en 1910, no sólo es evidente que no hay sitio para el poeta en la sociedad utilitaria que se ha instaurado, sino que ésta, al regirse por el criterio de economía y el uso racional de todos sus elementos para los fines productivos que se traza, debe destruir la antigua dignidad que le otorgara el patriciado al poeta y vilipendiarlo como una excrecencia social peligrosa. Ser poeta pasó a constituir una vergüenza. La imagen que de él se construyó en el uso público fue la del vagabundo, la del insocial, la del hombre entregado a borracheras y orgías, la del neurasténico y desequilibrado, la del droguista, la del esteta delicado e incapaz, en una palabra - y es la más fea del momento- la del improductivo. Quienes más contribuyeron a crear esta imagen fueron, porque no pueden ser otros, intelectuales, en especial los críticos tradicionalistas, verdaderos ideólogos de esta lucha contra el poeta que orienta la burguesía hispanoamericana, porque no distinguía mucho entre el peligro de un hombre dedicado a la poesía y el de un anarquista con su bomba en la mano" (Rama, 1995: 38).

Será entonces el intelectual ligado a los medios de comunicación quien comience su camino para convertirse en la conciencia moral de su sociedad. El nuevo régimen de significación ya no podía otorgarle al poeta dignidad alguna, quizás fue Baudelaire uno de los primeros en advertir este fenómeno cuarenta años antes en París (Benjamin, 1988). Ante el advenimiento de una nueva configuración económico cultural que se convertirá en pocas 
Álvaro Cuadra

décadas en la naciente industria cultural, es decir ante un nuevo modo de producir, distribuir y consumir los bienes simbólicos, la única posibilidad para los poetas fue la de convertirse en intelectuales.

Mientras la analogía del poeta y el anarquista lo volvía un personaje peligroso e indeseable, muy difícil de vindicar; el intelectual ligado a los libros de ideas como dispositivos de una gran industria editorial de gran tiraje, emergía como un líder de opinión y, en el límite, como ideólogo en una sociedad de masas convulsionada por revoluciones de distinto sello. El lugar del intelectual era discutido entre fascistas, marxistas y liberales, pero pocos se atrevían a negarle su espacio y dignidad.

En la actualidad, hay muchos que anuncian el fin de los intelectuales (Debray, 2001) De hecho, podemos constatar a diario que el nuevo sentido común ya no viene de ilustrados líderes de opinión, sino de los medios de comunicación y sus estrellas. Este nuevo estado de cosas remite, por cierto, a una reconfiguración cultural que, en toda su radicalidad, implica un nuevo régimen de significación: la hiperindustrialización de la cultura.

\section{Hiperreproducibilidad: hiperindustria cultural}

Antes de caracterizar la encrucijada en que se encuentra la figura del intelectual hoy, se hace indispensable introducir algunas distinciones teóricas a la escena comunicacional contemporánea. Entre las muchas acepciones que puede tener la noción de cultura está, ciertamente, aquella de índole comunicacional. En efecto, la cultura puede ser entendida en cuanto una cierta configuración o régimen de significación que estatuye límites y posibilidades en dos sentidos: en primer lugar, toda cultura genera un modo de producir, distribuir y consumir bienes simbólicos, es decir, toda cultura posee una dimensión económico cultural. En segundo lugar, y no menos importante, los límites y posibilidades de un cierto régimen de significación trazan el horizonte de lo concebible, esto es, las posibilidades del imaginario histórico social, tanto desde una dimensión perceptual como cognitiva. De esta manera, la cultura en tanto régimen de significación, no solo atañe a la dimensión objetiva del fenómeno sino también a la dimensión subjetiva. 
Álvaro Cuadra

Entre los primeros en advertir las mutaciones que traía consigo la industrialización de las comunicaciones se destaca la figura de Adorno, quien acuñó el concepto de kulturindustrie, para hacer evidente la producción seriada de bienes simbólicos. Por su parte, Walter Benjamin mostró con nitidez las implicancias del nuevo modo de significación, en cuanto una abolición del modo de existencia aurático de las obras y la subsecuente transformación del sensorium bajo la experiencia del shock.

El diagnóstico de los frankfurtianos bien merece ser revisado a más de cinco décadas, pues hoy resulta claro que a la reproducción mecánica advertida por Benjamin se suma la hiperreproducción digital, devenida una práctica social de bajo coste y sin pérdida de señal. Este panorama crea en los hechos las condiciones de posibilidad para una hiperindustrialización de la cultura, esto es, la expansión de una red capilar abierta y horizontal, que permite una comunicación, no centralizada al modo broadcast, sino el acceso de todos a todos, la modalidad podcast (Cuadra, 2007) (Véase cuadro $n^{\circ} 1$ ).

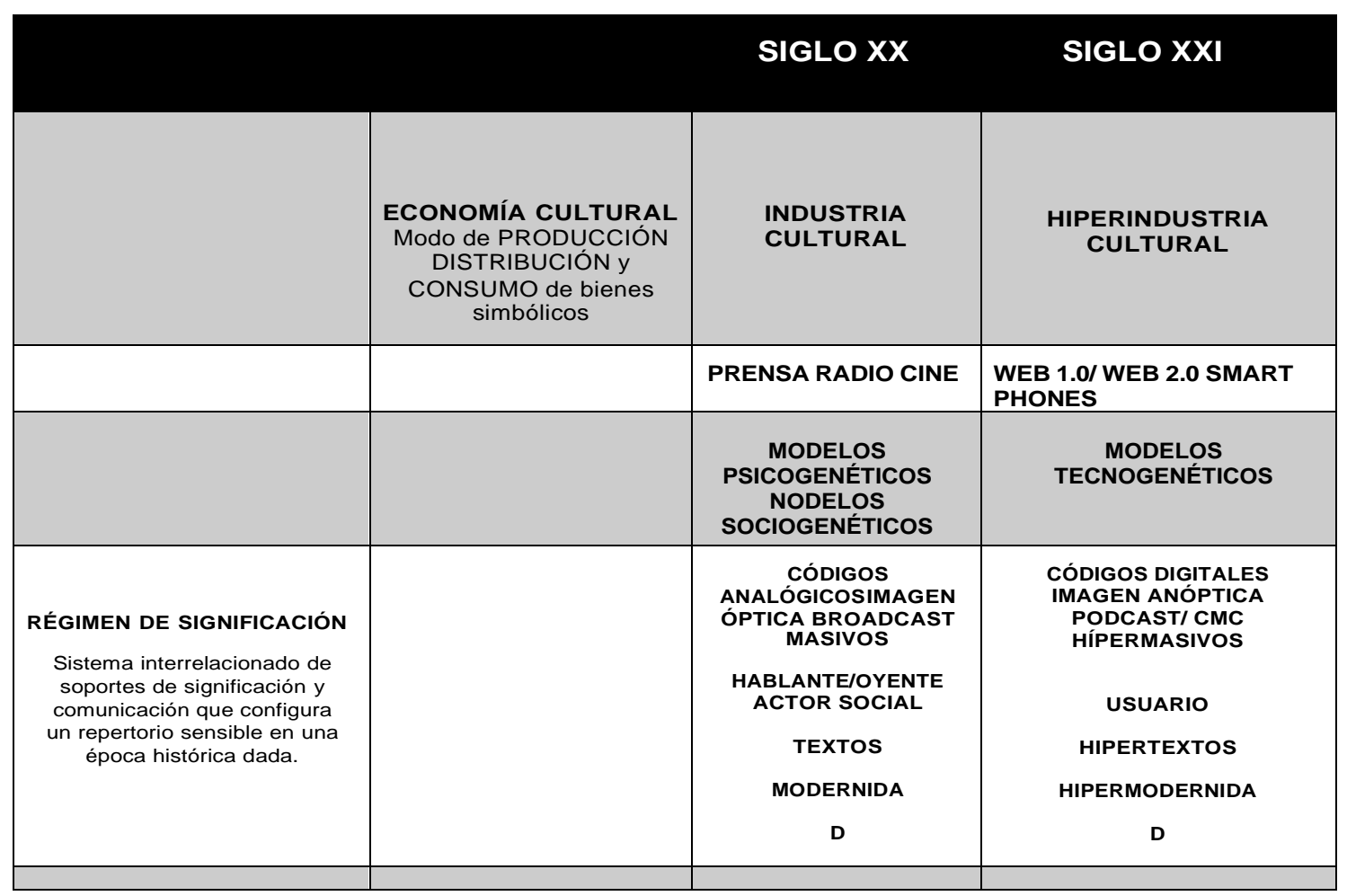




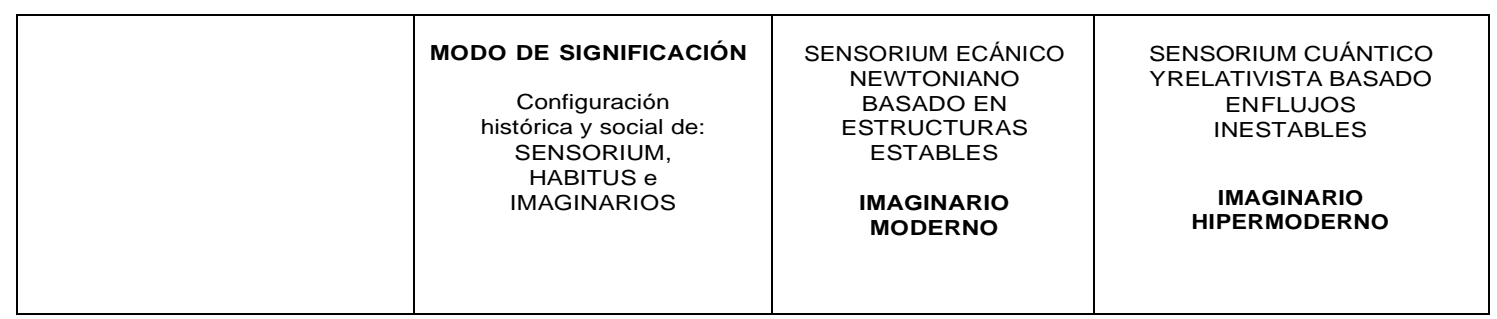

Cuadro $n^{\circ} 1$

La hiperindustria cultural, dirigida a públicos hipermasivos, es capaz de crear una sincronización plena entre los flujos temporales de conciencia y los flujos massmediáticos audiovisuales, transformando con ello la cardinalidad y calendariedad del imaginario social contemporáneo.

El plañidero reclamo ilustrado ante la actual cultura de masas, inmersa en las coordenadas de las sociedades de consumo, pretende instituir el momento de la reflexión y la convicción frente a un mundo de flujos orientado hacia la seducción, convirtiéndose en mera nostalgia ante un capitalismo libidinal cuyo epicentro no es sino el deseo.

La figura del intelectual nacido en una época en que el sensorium estuvo marcado por un régimen cuya configuración básica fue la grafósfera como matriz mental, se encuentra ahora en una encrucijada compleja ante el nuevo mundo de la videósfera, nuevo modo de percibir, conocer y pensar.

No olvidemos que el intelectual es la exaltación del individuo privilegiado, aquel sujeto de las sociedades burguesas que por sus virtudes y conocimientos era capaz de iluminar a las masas. El intelectual es el autor, la auctoritas, el propietario y origen de un discurso. Tal figura es impensable en un mundo plebeyo y más igualitario. El homo aequalis instituido como usuario y consumidor no es compatible con la noción de intelectual. Así, tanto la nueva división del trabajo, como una cultura igualitaria y consumista ligada genéticamente al espectáculo, no admite ni necesita intelectuales. En el Chile actual, por cierto, la videósfera ha desplazado la figura del intelectual por los rostros rutilantes de las estrellas. En las producciones massmediáticas ya nadie se ocupa del autor sino del superstar. Incluso el libro, como difusor de ideas, entra en crisis, produciendo un doble efecto: se expanden los públicos para las nuevas ideas, pero la vigencia de éstas es cada vez más efímera. La nueva Ciudad Virtual es una 
Álvaro Cuadra

sociedad más bien de "flujos" y no de "estructuras" estables: el intelectual clásico ha sido una construcción histórica que sucumbe ante el glamour digitalizado de las RSO (Redes Sociales On line) y los medios. La televisión instala un nuevo "sentido común", pues como afirma Beatriz Sarlo (1995):

"Hoy, el sentido común se teje con ideas que, literalmente, caen del cielo. La televisión es una de las filosofías del sentido común contemporáneo. El gran sacerdote electrónico habla frente a su pueblo y ambos, sacerdote y pueblo, se influyen: la televisión escucha los deseos de su público y responde a ellos; el público descubre que sus deseos son bastante parecidos a los que le propone la televisión" (Sarlo, 1995: 113).

\section{Los silencios de Caín}

Si hace un siglo, la figura de Caín se encarnó en el poeta que no encontró su lugar en las sociedades burguesas finiseculares, hoy en día el "expulsado del Paraíso" es el intelectual. Nuestra hipótesis apunta a un doble movimiento, por una parte, una transformación del régimen de significación en los albores del siglo XXI, esto es, una mutación simultánea de la dimensión económica cultural como de los modos de significación que excluye la figura histórica del intelectual. Pero, al mismo tiempo, el fenómeno posee un alcance político no menor: la extinción del pensamiento crítico. Así, entonces, el mentado "silencio de los intelectuales" remite tanto a una revolución cultural derivada de la convergencia tecnocientífica logística, y de telecomunicaciones que ha transformado los lenguajes de equivalencia de una cultura planetarizada, como a una hegemonía política de los flujos de capital devenido significantes digitalizados.

Asistimos a la paradoja en la cual pareciera que los intelectuales han enmudecido, precisamente, en el momento histórico en que se multiplican las "buenas causas" que bien merecen una reflexión seria: degradación de la biosfera, empobrecimiento de los medios de comunicación social, extensión global de la violencia y pauperización acelerada de gran parte de la humanidad. Como afirma Subirats: 
Álvaro Cuadra

"Definir este cambio histórico es una tarea compleja... Pero podemos formularlo provisionalmente a partir de tres constituyentes que definen la crisis civilizatoria de nuestro tiempo: primero, la destrucción de la biosfera; segundo, la eliminación de las memorias culturales; por último, el nihilismo, el principio ético y epistemológico autodestructivo que alimenta nuestro presente histórico" (Subirats, 2006: 143).

Si el presente representa ya un descalabro planetario nunca antes visto, las previsiones para el futuro inmediato resultan apocalípticas:

"La perspectiva sobre el futuro que arrojan estos cuadros sociales es simplemente aterradora. Presupone que una fracción creciente de la humanidad tiene que ser excluida del derecho a la supervivencia, ya sea en términos monetarios, sometiéndoles a políticas corruptas y economías de expolio, o bien bajo las restricciones, cada día más extremadas, al acceso social de los recursos naturales más elementales, como agua, tierra y aire no contaminados. El principio de esta exclusión ya ha sido formulado por las políticas y las élites de las grandes corporaciones y organizaciones militares mundiales a lo largo del 2003. Y se ha hecho precisamente en los foros y las cumbres de las Naciones Unidas" (Subirats, 2006: 139).

Frente a esta verdadera distopía convertida por la híperindustria cultural en imágenes cotidianas, la figura del intelectual se encuentra sintomáticamente ausente. Tal parece que su ausencia es condición de posibilidad para que la pesadilla siga adelante, esto es lo que piensa nuestro autor cuando señala: "Este proceso de regresión cultural no podría tener lugar sin una condición preliminar: el silencio de los intelectuales bajo cualquiera de sus manifestaciones, ya sean artísticas o académicas, periodísticas o literarias" (Subirats, 2006: 165).

Este silencio de los intelectuales no obedece, desde luego, a la voluntad del estamento académico o artístico. Se trata más bien de una mutación del régimen de significación que 
Álvaro Cuadra

acompaña un proceso todavía mayor cual es la nueva configuración del capital a escala global. Como denuncia Subirats:

"Lo que quiero denunciar es más bien que este artista o intelectual ha sido aislado y trasformado, y en última instancia eliminado a través de las normas de la industria cultural y de la reconfiguración de la vida académica bajo las categorías corporativas de departamentalización y profesionalidad" (Subirats, 2006: 166).

La conclusión de Subirats es apasionada y rotunda: "Bajo la primacía absoluta de la ficcionalización de lo real y de la reducción de la cultura a entertainment se han eliminado las voces y las tradiciones intelectuales más lúcidas del siglo XX como si no fueran otra cosa que un deliro superfluo" (Subirats, 2006: 166).

Se advierte en nuestro pensador un cierto talante ilustrado que, al igual que Adorno, desconfía de las RSO, los medios masivos y del entertainment, reponiendo en cierto modo un debate de los años sesenta (Eco, 1995). Nos interesa destacar, sin embargo, la primera afirmación en torno a una "ficcionalización de lo real". Efectivamente, la hiperindustrialización de la cultura logra una sincronización plena entre los flujos temporales de conciencia y los flujos digitales y mediáticos, produciendo una "ficcionalización de lo real", modo oblicuo de afirmar que los medios de comunicación han alcanzado la capacidad para "fabricar" el presente histórico. Aquí conviene separar el tiempo histórico del tiempo informacional. En la experiencia de una temporalidad histórica, la "serie fáctica" se nos presenta como una secuencia de eventos que sigue el "ritmo natural" de la existencia humana. Por el contrario, en la experiencia de la "temporalidad informacional", la "serie fáctica" se nos presenta como una secuencia de eventos que sigue el "ritmo de las redes informacionales".

\section{El ocaso de la crítica}


Álvaro Cuadra

Cualquiera sea la envergadura de la pesadilla en que estemos inmersos, es innegable que ésta se nos ofrecerá como una virtualidad HD (High Definition). Nada de este virtuosismo tecnológico, empero, le resta urgencia y legitimidad al reclamo del filósofo:

"La alegre banalización y la subsiguiente abdicación de las tradiciones críticas en las culturas de los cuatro continentes, la insolidaridad con las resistencias y protestas sociales en nombre de la superación de los sujetos históricos, y la celebración de la cultura como espectáculo han enmudecido a esa intelligentsia tachada frente a lo que hoy se exhibe obscenamente como sus últimas consecuencias: la trivialidad de la guerra como videojuego, la deconstrucción estadística de la democracia como performance, y una devastación de ecosistemas, comunidades humanas y culturas de magnitudes incontrolables bajo el espectáculo global de paraísos comodificados y una arcaica impasibilidad social" (Subirats, 2006: 167).

El ocaso de la figura del intelectual es un proceso histórico y cultural en curso, derivado de una acelerada hiperindustrialización de la cultura. No obstante, el reclamo de Subirats encuentra su asidero en algo todavía más profundo: no se trata del fin del pensamiento sino más bien del ocaso de un cierto pensamiento crítico. Así, un proceso histórico y cultural es, al mismo tiempo, un proceso político.

La situación es inquietante pues, a fines del siglo XIX, la figura del poeta se desplazó hacia la del intelectual, lo que le garantizó cierta dignidad en las nuevas coordenadas económico-culturales. Recordemos que, finalmente, los poetas de fines del siglo XIX lograron instalarse en las nuevas coordenadas culturales, transformándose en intelectuales. Al respecto Rama señala:

"Pero había un modo oblicuo por el cual los poetas habrían de entrar al mercado, hasta devenir parte indispensable de su funcionamiento, sin tener que negarse a sí mismos por entero. Si no ingresan en cuanto poetas, lo harán en 
cuanto intelectuales. La ley de la oferta y la demanda, que es el instrumento de manejo del mercado, se aplicará también a ellos haciendo que en su mayoría devengan periodistas. En efecto, la generación modernista fue también la brillante generación de los periodistas, a veces llamados a la francesa “chroniqueurs", encargados de una gama intermedia entre la mera información y el artículo doctrinario o editorial, a saber: notas amenas, comentario de las actualidades, crónicas sociales, crítica de espectáculos teatrales y circenses, eventualmente comentario de libros, perfiles de personajes célebres o artistas, muchas descripciones de viaje de conformidad con la recién descubierta pasión por el vasto mundo. Cronistas específicamente fueron Gómez Carrillo y Vargas Vila, pero también lo fueron Gutiérrez Nájera y Julián del Casal, y, sobre todo, los dos mayores: Martí y Darío” (Rama, 1995: 160).

La situación en la actualidad es muy otra: el intelectual no encuentra un locus al cual pudiera desplazarse. Las categorías de experto o consultor, así como la de académico requieren no sólo de una alta especialización sino que exigen las más de las veces una mirada pretendidamente "científica y objetiva", esto es, despolitizada. Por lo demás, el campo laboral de los expertos y consultores está constituido por gobiernos, corporaciones u organismos multinacionales cuyos intereses están predeterminados. Por otra parte, el espacio en las universidades de toda América Latina no solo se ha profesionalizado sino que además se ha privatizado, al punto de convertir, muchas veces, los centros de estudios superiores en verdaderos “Think Tanks” de gobiernos y empresas transnacionales.

En las actuales circunstancias, cualquier reivindicación de la tradición crítica supone la exclusión de los circuitos legitimados. Así como el poeta fue degradado hacia fines del siglo XIX a la condición de anarquista y peligroso; hoy, el pensamiento crítico, y con ello la figura del intelectual y académico, es degradado a la condición de lo marginal y lo excéntrico, cuando no, a cómplice de la violencia y el terrorismo. El académico intelectual de tradición crítica carga con la marca de Caín y es, en el mejor de los casos, un molesto diletante muy lejano de aquella conciencia moral de otrora. La nueva conciencia moral está ahora instalada en los influencers de 
las RSO y en todos los medios hipermasivos que transmiten en tiempo real la historia pasada, presente y futura de la humanidad.

\section{Espectáculo y Barbarie}

La figura del intelectual ha quedado atrapada en un doble movimiento que, como una telaraña, se expande por el mundo entero. Primero, el mismo desarrollo de la industria cultural que catapultó a los intelectuales hasta los años setenta, hoy los sepulta al desplazar su "lenguaje de equivalencia" desde la escritura a lo multimedial digitalizado en red. La hiperindustrialización de la cultura, forma contemporánea de los flujos simbólicos hipermasivos, hipermediales y anclados a la estética del shock, deja fuera el pensamiento deliberativo-reflexivo-crítico inherente al ejercicio escritural y toda forma de actividad intelectual. Segundo: la caída del muro como exteriorización de una crisis mayúscula de los metarrelatos de la modernidad y de sus excesos, ha creado las condiciones de posibilidad para un nuevo ethos, sea que le llamemos postmodernidad, hipermodernidad o postcomunismo.

El nuevo ethos entraña, qué duda cabe, serios riesgos políticos, pues tal como ha señalado Eagleton:

"El pensamiento postmoderno del fin-de-la-historia no nos augura un futuro muy diferente del presente, una imagen a la que ve, extrañamente, como motivo de celebración. Pero hay en realidad un futuro posible entre otros, y su nombre es fascismo. La gran prueba del postmodernismo o, por lo que importa, de toda otra doctrina política, es cómo zafar de esto. Pero su relativismo cultural y su convencionalismo moral, su escepticismo, pragmatismo y localismo, su disgusto por las ideas de solidaridad y organización disciplinada, su falta de una teoría adecuada de la participación política: todo eso pesa fuertemente contra él” (Eagleton, 1998: 197).

Bastará tener en mente la llamada Global War contra el terrorismo, que supone un estado de guerra permanente, difusa y que compromete al planeta en su totalidad. Una guerra, 
por cierto, que supera el llamado "complejo militar industrial" de mediados del siglo XX e inaugura el "complejo militar mediático". Lo mediático y lo militar son dos componentes fundamentales que nos traen a la mente el concepto de fascismo. Como escribe Subirats:

"Bajo esta doble constelación el nuevo poder mediático y militar global ha creado aquella misma condición objetiva elemental bajo la que Walter Benjamin o Pier Paolo Pasolini definieron el fascismo moderno: el estado general de impotencia de una humanidad disminuida a la función de espectador y consumidor de su propia destrucción" (Subirats, 2006: 163).

Desde otra perspectiva, este nuevo ethos cultural excluye la figura del intelectual como artífice de nuevas ideas. El nuevo estatuto del saber y la imaginación teórica se ha tornado "perfomativo" e interdisciplinario. (Lyotard, 1987). Hoy son los equipos de "expertos" los que generan "nuevas jugadas" en la pragmática del saber:

"En un mundo como el que hemos descrito, la figura del "maestro" o “profesor” resulta problemática, cuando no agónica. Si los sistemas nemotécnicos de producción de retenciones terciarias, y con ello del imaginario contemporáneo, lograron abolir la figura del "intelectual” al estilo de Zolá, el nuevo estatuto del saber pone en crisis al "profesor”: “...la deslegitimación y el dominio de la performatividad son el toque de agonía de la era del Profesor: éste no es más competente que las redes de memoria para transmitir el saber establecido, y no es más competente que los equipos interdisciplinarios para imaginar nuevas jugadas o nuevos juegos" (Lyotard, 1987: 98).

Aclaremos que cuando afirmamos el ocaso de la figura histórica del intelectual, nos referimos a aquello que Walzer denomina "crítico social” cuando escribe: 
Álvaro Cuadra

"Sin duda las sociedades no se critican a sí mismas: los críticos sociales son individuos, pero también son la mayor parte del tiempo, miembros que hablan en público a otros miembros que se incorporan al habla y cuyo discurso constituye una reflexión colectiva sobre las condiciones de la vida colectiva" (Walzer, 1993: 39).

\section{La intelligentsia en redes}

La extinción de los intelectuales ha generado un vacío que es llenado a diario por las RSO y los medios digitales Son ellos los encargados, no solo de regular el registro y el tono de los grandes temas (trending topics), sino de proponer a su público hipermasivo el repertorio de temas que merecen nuestra atención. El lugar de la "convicción” que alguna vez ocupó el docto intelectual ha sido barrido del imaginario contemporáneo por el lugar de la "seducción" propio del comentarista o influencer.

Si otrora fueron los "publicistas" y luego los "comentaristas" y "expertos", los que se ocupaban de tópicos específicos: comentario político, económico, artístico, entre muchos, hoy, en una sociedad hipermediatizada, la voz del influencer adquiere relevancia por dos razones: primero, habita el mismo "sentido común” de sus followers, su relación es horizontal, creando una inmediatez psíquica y social con su público. El buen influencer no es ni más instruido ni más perspicaz que su público, es un igual: habla como la mayoría, piensa como la mayoría, actúa como la mayoría. Segundo, la mayoría de los seguidores de redes en una hipercultura de masas se aproxima, como hemos señalado, a una cierta cultura internacional popular, pero, dirigida precisamente por las grandes coordenadas del consumo mediático y suntuario. En este sentido, se trata de una masa cuyos estereotipos vienen desde el universo hipermediático de manera vertical y no desde las profundidades antropológicas y folklóricas de la cultura popular clásica. La hipercultura de masas es más plebeya que popular.

El influencer se distingue del intelectual en cuanto se trata de un animal digital, espacio en que se legitima al emitir opinión. El influencer es el cúlmen del homo aequalis, no hay distancia respecto de su público hipermasivo. Esta nueva figura no apela a episteme alguno, su 
Álvaro Cuadra

saber se instala en el sentido común que no reconoce límites. Su discurso plebeyo contornea el imaginario de los "enjambres digitales", desde lo sentimental y melodramático a la opinión política promedio. Lejos de cualquier relación asimétrica, el influencer encarna y expresa la Vox Populi, la dimensión cotidiana y obvia de la existencia. En las antípodas del intelectual, el influencer habita el mundo digital y audiovisual de las redes; pariente lejano del comediante, el orador y el clown.

Con todo, cuando algún intelectual entra al mundo on line, lo hace al precio de travestirse en un showman, sea como comentarista o influencer. Es más, la figura del intelectual es caricaturizada por los clichés de la farándula: un personaje excéntrico, gris, opaco y denso que habla un lenguaje incomprensible. El pensamiento y el saber solo son valorados en cuanto productivos y utilitarios, basta revisar las expectativas educacionales de los padres en relación a sus retoños. El conocimiento vale solo en tanto dato.

Al comenzar este siglo XXI vemos periclitar la figura centenaria del intelectual como exteriorización de una mutación mucho más profunda. Asistimos al ocaso de aquella "ciudad letrada" descrita por Ángel Rama en su obra homónima y al advenimiento de la "ciudad virtual", Los áulicos espacios de nuestras bibliotecas van cediendo poco a poco a las bases de datos que se multiplican en la red, el “dataísmo”. Byung Chul Han (2020) ha llegado a concebir lo que él llama "giro dataísta":

"Hoy se está produciendo de forma silenciosa un nuevo cambio de paradigma. El giro antropológico copernicano, que había elevado al hombre a productor autónomo del saber, es reemplazado por un giro dataísta. El hombre debe regirse por datos. Abdica como productor de saber y entrega su soberanía a los datos. El dataísmo pone fin al idealismo y al humanismo de la Ilustración. El hombre ha dejado de ser sujeto cognoscente soberano, autor del saber. Ahora el saber esproducido maquinalmente" (Han, 2020: 60).

Es ya un lugar común denunciar cómo las seductoras redes digitales y sus derivados van desplazando a los libros y a la lectura. El siglo XXI es el siglo del bullicio, vivimos la 
saturación de imágenes y sonidos, nuestras metrópolis están inundadas de mercancías, ruido, luces y pancartas digitales. Pero, paradojalmente, éste es el tiempo en que las ideas radicalmente nuevas y creativas se han tornado más escasas que nunca. En ese sentido, este es también un tiempo de censuras y silencios, el tiempo de la medianoche en la historia contemporánea

\section{Medianoche en la historia}

"Soberano es el que decreta el estado de excepción" (Carl Schmitt. Politische Theologie. Leipzig, 1934) (Schmitt, 2009)

El mundo entero entra en un "estado de excepción" y no se trata, como pudiera pensarse, de una cuestión meramente político-jurídica. Como ya escribiera Walter Benjamin: “La tradición de los oprimidos nos enseña que el 'estado de excepción' en el que vivimos es la regla" (Benjamin, 2008: 43).

La pandemia actual marca un tiempo de oscuridad, es el momento en que la muerte se enseñorea por aldeas y metrópolis, es la medianoche de la historia humana. ${ }^{1}$ Como uno de los jinetes del apocalipsis, la peste pisotea toda vana ilusión del Fausto moderno.

En América Latina, la "tradición de los oprimidos" adquiere el tinte de la pobreza y la exclusión más que centenaria, todo en nombre del "progreso" La peste ha desnudado todo engaño, por ejemplo, ya no más la "Cidade de Deus" sino la triste "favela”, el lugar donde el coronavirus ha puesto en primer plano la miseria y la muerte en Río de Janeiro.

No seamos ingenuos, nuestro asombro no nace de la conjunción entre "progreso" y "miseria". No olvidemos que ha sido, precisamente, la promesa moderna de "progreso" la que ha hecho posible aquella miseria extrema, la "barbarie" del fascismo. Una "barbarie", por cierto, que no tiene nada de anacrónico o extemporáneo; muy por el contrario, ha sido una experiencia muy contemporánea para los oprimidos, hasta el actualgobierno de Bolsonaro.

\footnotetext{
${ }^{1}$ Las grandes ciudades de todo el mundo hoy aparecen vacías. La presencia humana ha sido abolida. Como los espacios de París fotografiados por Atget, precursor del surrealismo, las ciudades parecen celebrar la ausencia y el silencio, "la ciudad está desamueblada" dirá Benjamin. Paisajes desiertos expurgados de la contaminación y de toda ingenuidad.
} 
En el caso de Chile, llama la atención cómo la dictadura de Augusto Pinochet cristalizó sus ideales en la llamada "Constitución de 1980", una figura político-jurídica que instala de suyo un "estado de excepción" que se ha prolongado ya por cuatro décadas.

La dictadura chilena, mediante la proclamación de una nueva Constitución, suspende todo el orden anterior y lo hace mediante la violencia. La suspensión del derecho depende siempre de la voluntad de los poderosos y esa voluntad se expresa como violencia. Es la violencia la que ha creado el derecho y es ella la que lo ha mantenido hasta el presente.

El "estado de excepción” creado por Augusto Pinochet, erige al dictador en soberano. Por tanto, cuando el "estallido social" del 18/0 pone fin al "oasis" latinoamericano y reclama una nueva Constitución para Chile, lo que en verdad se reclama es la posibilidad de devolver la soberanía al pueblo.

Cuando Walter Benjamin escribe que para los oprimidos el "estado de excepción” es la regla, se está afirmando de manera categórica que ni la democracia liberal ni el melifluo discurso de los derechos humanos ni todo el "progreso" económico que reclama para sí la globalización neoliberal pueden ocultar el hecho fundamental de que tales presuntos logros se han hecho sobre las espaldas de los menesterosos y desde una visión eurocéntrica y racista ${ }^{2}$. En suma, la riqueza de unos pocos produce, ineluctablemente, la miseria de los muchos.

En esta historia a medianoche, los nuevos sujetos sociales -aquel híbrido que podemos reconocer como la conjunción de un Usuario y un Consumidor- se aglomeran como verdaderos "Enjambres Digitales" (Han, 2014) en las Redes Sociales On line, mientras las pantallas del mundo muestran cadáveres diseminados en las calles de muchas ciudades del mundo con la asepsia de un laboratorio de criminalística UHD (Ultra High Definition) y aumentan las "medidas de emergencia" ejecutadas por los ejércitos de todos los países ${ }^{3}$.

En esta oscura medianoche de nuestra historia, la figura del intelectual está casi extinta, expurgado de universidades y casas editoriales, expulsado de cualquier paraíso, deambula como

\footnotetext{
${ }^{2}$ El director de la Organización Mundial de la Salud (OMS), Tedros Adhanom Ghebreyesus, ha condenado con firmeza lo que denominó "declaraciones racistas" de dos científicos franceses que en días pasados propusieron que África fuera "terreno de prueba" de vacunas contra el coronavirus (Diario El País. España 06 de abril 2020).

${ }^{3}$ La alta comisionada de Naciones Unidas para los Derechos Humanos, Michelle Bachelet, expresó hoy su temor a que algunas medidas de emergencia tomadas para hacer frente al COVID-19 sean usadas como justificación para introducir "cambios represivos" que se prolonguen incluso cuando termine la pandemia (El País, 09 de abril de 2020).
} 
Álvaro Cuadra

un indigente Caín. En estos tiempos de peste, es un desempleado más en las grandes ciudades. Aquella que fuera reclamada como la conciencia crítica de la sociedad, camina hoy adormecida detrás de una profiláctica mascarilla.

En esta oscura medianoche de nuestra historia, la destrucción y la muerte se han convertido en un macabro espectáculo: un mundo en "estado de excepción" donde toda norma ha sido suspendida, mas no para el "carnaval" sino para el sometimiento a la decisión del soberano.

\section{Bibliografía}

El País (2020). “Noticias sobre la actualidad internacional”, en El País, recuperado de https://www.eldiario.es/internacional. 09 de abril de 2020.

Benjamin, W. (1988). "El París del segundo Imperio en Baudelaire”. En Poesía y Capitalismo. Madrid: Taurus.

Benjamin, W. (2008) Tesis sobre la historia y otros fragmentos. México DF: Ítaca.

B-C, Han (2014). En el enjambre. Barcelona: Herder.

B-C, Han (2020). La desaparición de los rituales. Barcelona: Herder.

Cuadra, A. (2008). Hiperindustria Cultural. Santiago: Edixiones Arcis.

Debray, R. (2001) “Muerte de un centenario: el intelectual” (03 junio 2001). En El País.

Recuperado de: www.elpais.es/opinion. 03 de junio de 2001.

Eagleton,T. (1998). Las ilusiones del postmodernismo. Buenos Aires: Paidós.

Eco, U. (1995). Apocalípticos e integrados. Barcelona: Editorial Lumen. 


\section{Álvaro Cuadra}

Lyotard, J.F (1987). La condición postmoderna. Buenos. Aires: REI.

Rama, Á. (1995). “Los poetas modernistas en el mercado económico”. En Rubén Darío y el Modernismo. España: Alfadil Ediciones.

Sarlo, B. (1995). Todo es televisión. En Instantáneas: Buenos Aires: Ariel.

Schmitt, C. (2009). Teología política. Madrid: Trotta Editorial.

Subirats, E. (2006). Violencia y civilización. Madrid: Losada.

Walzer, M. (1993). Interpretación y crítica social. Buenos Aires: Ediciones Nueva Visión. 